\title{
PACIENTE VÍTIMA DE VIOLÊNCIA NO TRÂNSITO: ANÁLISE DO PERFIL SOCIOECONÔMICO, CARACTERÍSTICAS DO ACIDENTE E INTERVENÇÃO DO SERVIÇO SOCIAL NA EMERGÊNCIA
}

\author{
A PATIENT VICTIM OF CAR TRAFFIC VIOLENCE: AN ANALYSIS OF SOCIOECONOMIC PROFILE, \\ ACCIDENT CHARACTERISTICS AND SOCIAL SERVICES INTERVENTION IN THE EMERGENCY ROOM
}

\author{
Kátia Campos dos Anjos ${ }^{1}$, Maria Rosa Barral Evangelista ${ }^{2}$, Jorge dos Santos Silva ${ }^{3}$, Arnaldo Valdir Zumiotti ${ }^{4}$
}

\begin{abstract}
RESUMO
Objetivo: Identificar e analisar o perfil dos pacientes; o meio de transporte que causou o acidente; as normas do Código de Trânsito Brasileiro, se foram ou não seguidas; a rede de apoio e as intervenções do Serviço Social. Método: A pesquisa foi realizada com $100 \%$ dos pacientes internados nesta Instituição no período de 15/08/04 a 19/11/04, que foram vítimas de acidente no trânsito. Entrevistamos: 37 condutores de motocicletas, 26 pedestres, 15 condutores de veículo a motor e 06 passageiros, totalizando 84 pacientes. Foram utilizados formulários com questões abertas e fechadas de abordagem quantitativa e qualitativa. Resultado: A maior demanda foi de motociclistas, sendo que $83 \%$ são do sexo masculino, jovens com escolaridade até o ensino médio e renda mensal de dois salários mínimos. 62\% residem em São Paulo e somente $36,5 \%$ possuem vínculo formal de trabalho. A maior parte das fraturas ocorreu nos membros inferiores (54\%). Todos os pacientes necessitaram de cuidados após alta hospitalar, sendo que 98\% contaram com o apoio familiar. Conclusão: Os elevados números de acidentes nos indicam que a violência no trânsito pode ser considerada um problema de saúde pública e estudos devem ser realizados para subsidiar as políticas públicas nesta área.
\end{abstract}

Descritores: Acidente de trânsito; Caracterização e análise das vítimas; Intervenções do Serviço Social.

Citação: Anjos KC, Evangelista MRB, Santos-Silva J, Zumiotti AV. Paciente vítima de violência no trânsito: análise do perfil socioeconômico, características do acidente e intervenção do Serviço Social na emergência. Acta Ortop Bras. [periódico na Internet]. 2007; 15(5):262-266. Disponível em URL: http://www.scielo.br/aob.

\section{INTRODUÇÃO}

Nas últimas décadas ocorreram grandes transformações no Brasil, principalmente os avanços nas indústrias automobilísticas que geraram efeitos multiplicadores de transformações urbanas e sociais Todos esses avanços e mudanças tecnológicas fizeram com que o crescimento da cidade acontecesse de forma desordenada, sem infra-estrutura adequada, e os centros urbanos não acompanharam o crescimento da frota de veículos. A qualidade insatisfatória dos transportes coletivos fez com que as pessoas optassem por meios de transportes individuais, o que piorou os problemas de trânsito nas grandes cidades.

Os acidentes de trânsito e as variáveis que os circundam: comportamento humano, tecnologia, engenharia de tráfego, entre outras, têm sido foco de preocupação social. As modificações do novo Código de Trânsito Brasileiro (CTB) foram uma tentativa do Governo e da sociedade brasileira no sentido de reverter as alarmantes estatísticas do trânsito no Brasil. A nova lei prevê punições mais severas para os infratores: multas de valores elevados, possibilidade de perda da habilitação e a criação de mecanismos jurídicos para punir os crimes de trânsito (morte provocada por acidente) ${ }^{(1)}$

\section{SUMMARY}

Objective: To identify and analyze patients' profile; the means of transportation that caused the accident; whether the rules of the Brazilian Traffic Code were respected or not; and the support network and actions of social services. Methods: A survey was conducted with $100 \%$ of the patients admitted in this institution between August 15th and November 19th, 2004, who were victims of car accidents. We interviewed 37 motorcycle riders, 26 pedestrians, 15 drivers and 6 passengers, totaling 84 patients. Forms with open and closed questions, adopting both a quantitative and a qualitative approach were used. Results: The greatest demand was from motorcyclists, of whom $83 \%$ were male, youngsters, who had graduated in high school, with a monthly income equivalent to two minimum wages. Sixty-two percent lived in São Paulo and only 36.5\% had a formal job. Most fractures were on the lower limbs (54\%). All the patients required further care after hospital discharge and 98\% received support from their families. Conclusion: The high number of accidents indicates that traffic violence may be considered a public health problem and there is much to be investigated for the formulation of public policies in this field.

Keywords: Traffic accident; Characterization and analysis of the victims; Social Service interventions.

Citation: Anjos KC, Evangelista MRB, Santos-Silva J, Zumiotti AV. A patient victim of car traffic violence: an analysis of socioeconomic profile, accident characteristics and social services intervention in the emergency room. Acta Ortop Bras. [serial on the Internet]. 2007; 15(5):262-266. Available from URL: http://www.scielo.br/aob.

Na literatura científica temos alguns dados relevantes a respeito deste tema:- a medicina ortopédica discute a sub-especialidade em trauma devido à crescente demanda de acidentes de trânsito(2); o SUS (Sistema Único de Saúde) gasta mais com traumas do que com doenças ${ }^{(3)}$; -os acidentes de trânsito chegam a custar no mundo cerca de US\$ 8 bilhões por ano e no Brasil R $\$ 3,6$ bilhões (abril de 2003) segundo pesquisa realizada pelo IPEA ${ }^{(4)}$ sob a denominação "Impactos sociais e econômicos dos acidentes de trânsito nas aglomerações urbanas". O custo foi determinado com base no tratamento e reabilitação das vítimas, na recuperação ou reposição dos bens materiais danificados, no custo administrativo dos serviços públicos envolvidos e nas perdas econômicas e previdenciárias.

Calcula-se que, nos últimos 20 anos, 12 milhões de pessoas perderam a vida em acidentes de trânsito e 250 milhões sofreram os mais variados tipos de ferimentos. A máquina gerou um problema de saúde pública ${ }^{(5)}$.

No ano de 2003, o Ministério da Saúde ${ }^{(6)}$ registrou no Brasil 30.567 mortes de pacientes vítimas de trânsito. Segundo Correa Leite* ${ }^{\star}$ os

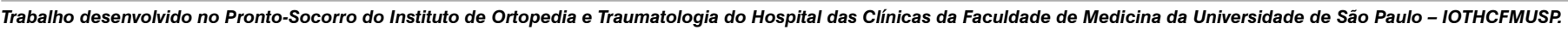
Endereço para Correspondência: Rua Dr. Ovídio Pires de Campos, 333 - Cerqueira César - São Paulo - São Paulo, Cep: 05403-010 - E-mail: camposdosanjos@yahoo.com.br

1. Assistente Social do Instituto de Ortopedia e Traumatologia do Hospital das Clínicas da FMUSP.

2. Assistente Social Chefe do Instituto de Ortopedia e Traumatologia do Hospital das Clínicas da FMUSP.

3. Médico Diretor do Pronto-Socorro do Instituto de Ortopedia e Traumatologia do Hospital das Clínicas da FMUSP.

4. Professor Titular do Departamento de Ortopedia e Traumatologia da Faculdade de Medicina da Universidade de São Paulo.

Trabalho recebido em 29/11/06 aprovado em 05/07/07 
acidentes automobilísticos, atendidos pelo Corpo de Bombeiros da cidade de São Paulo, contabilizaram em 200327.864 atendimentos, dos quais 474 foram vítimas fatais. Os dados até outubro de 2004 foram 21.863 atendimentos com 313 vítimas fatais.

O Pronto-Socorro do Instituto de Ortopedia e Traumatologia do Hospital das Clínicas da FMUSP atende pacientes portadores de afecções ósseas de ambos os sexos, sem limite de idade, das mais variadas regiões da cidade e do país, pelo SUS e Convênios. Esta Instituição é considerada referência na área da saúde, em tecnologia e atendimento de casos de alta complexidade. O serviço de emergência médica além de receber casos por demanda espontânea da população, atende acidentes automobilísticos, motociclísticos, quedas de maneira geral, agressões, lesões ósseas, ortopédicas e traumatológicas. Atende também grande demanda de pacientes encaminhados de outros hospitais, resgates, bombeiros, Polícia Civil e Militar.

O Serviço Social observou o número crescente de acidentados no trânsito. Isto gerou uma inquietação que nos levou à realização de uma pesquisa para melhor conhecer essa realidade. Procuramos identificar e analisar o perfil dos pacientes vítimas da violência no trânsito, o meio de transporte que causou o acidente, as normas do Código de Trânsito Brasileiro seguidas ou não pelos pacientes. Também nos propusemos a verificar as intervenções do Serviço Social e analisar a percepção do paciente em relação à internação hospitalar e sua rede social de apoio.

\section{MATERIAL E MÉTODO}

A pesquisa foi realizada com pacientes vítimas de acidentes de trânsito internados no Pronto-Socorro entre 15/08/04 a 19/11/04. Neste período foram internados 389 pacientes, sendo que $22 \%$ devido a acidente de trânsito (Figura 1). O instrumento de pesquisa foi dividido em: dados pessoais, situação socioeconômica, acidente de trânsito e rede social de apoio. No item acidente de trânsito utilizamos quatro formulários distintos para cada tipo de paciente: motorista de veículo a motor; motorista de motocicleta; pedestre e passageiro. Os formulários continham questões abertas e fechadas de abordagem quantitativa e qualitativa. As questões foram aplicadas nos pacientes após concordância e assinatura do Termo de Consentimento Livre e Esclarecido. Na abordagem quantitativa utilizamos análise estatística e na abordagem qualitativa, a metodologia do "discurso do sujeito coletivo"(7) que consiste em extrair de cada depoimento as expressões chaves que são as particularidades do pensamento que se assemelham, e as idéias centrais que são a expressão que descreve de forma sintética o depoimento analisado, gerando um discurso único. A pesquisa foi aplicada em 84 pacientes, 100\% da amostra do período: 15 condutores de veículo a motor; 37 condutores de motocicletas: 06 passageiros e 26 pedestres (Figura 2).

Devido às particularidades de cada tipo de acidente apresentaremos os resultados separando-os de acordo com cada tipo de paciente.

\section{Condutor de Veículo a Motor}

Foram entrevistados 15 pacientes condutores de veículo a motor: $54 \%$ são jovens entre 18 e 28 anos dos quais 93\% do sexo masculino. De acordo com Montal(5), "a habilitação do jovem condutor de veículos automotores representa verdadeiro rito de passagem no mundo moderno....os desafios somados à inexperiência na condução de veículos, o desconhecimento das normas de trânsito, a facilidade no uso do álcool, a sensação de invulnerabilidade causando a impressão de imortalidade, fruto da falta de consciência de risco".

Dos entrevistados: - 40\% possuíam ensino médio completo; - 46\% possuem vínculo formal de trabalho (Tabela 1); - 47\% são casados.

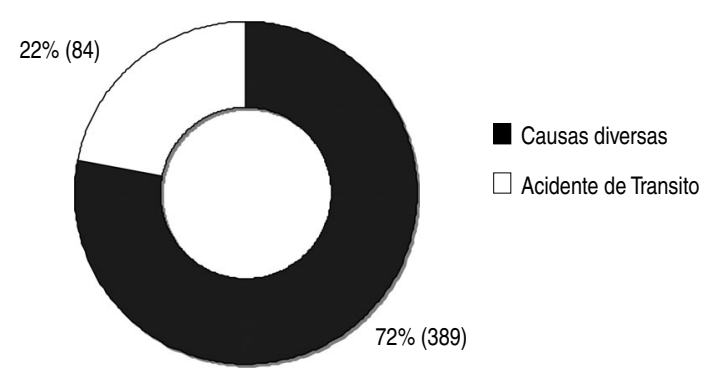

Figura 1 - Causa das internações no Pronto-Socorro do Instituto de Ortopedia e Traumatologia no período de 15/08/2004 a 19/11/2004.

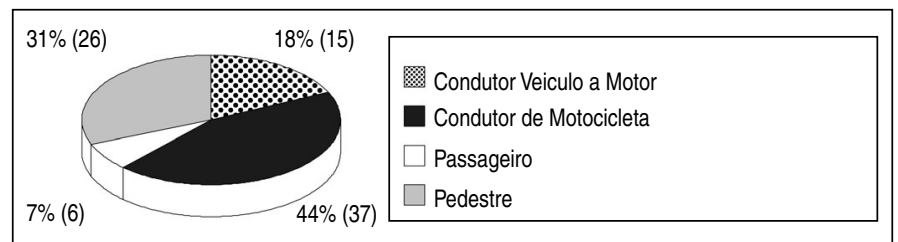

Figura 2 - Total de pacientes entrevistados que foram internados no ProntoSocorro, por tipo de acidente, no período de 15/08/2004 a 19/11/2004.

Grande parte dos acidentes ocorreu durante a semana (67\%), o horário de maior freqüência dos acidentes foi das 12 h01 às 18 horas (46\%) e 60\% estavam em horário de trabalho. Vale salientar que os acidentes de final de semana (80\%) foram de madrugada e 53\% dos condutores do veículo a motor não possuíam seguro particular do automóvel (Tabela 2).

Destacamos que o socorro a estes acidentados foi feito em $46 \%$ pelo Resgate e $26 \%$ pelo helicóptero da Polícia Militar, o que evidencia a eficiência destes serviços. Verificamos que $74 \%$ usavam cinto de segurança e 93\% possuíam habilitação para dirigir.

\section{Condutor de Motocicletas}

Foram entrevistados 37 condutores de motocicletas internados no período da pesquisa: 95\% do sexo masculino; a faixa etária mais representada situa-se entre 29 a 38 anos (43\%), seguida por jovens de 18 a 28 anos (41\%). Segundo Bastos Junior apud Sparti(8), "na cidade de São Paulo, 50\% dos acidentes fatais com motociclistas acontecem com pessoas com menos de vinte e quatro anos, 23\% dos acidentes de trânsito com morte envolvem adolescentes".

Quanto ao nível de escolaridade 35\% possuíam ensino médio completo, 62\% são casados, 43\% trabalham informalmente, sem vínculo empregatício, ou seja, à margem das leis trabalhistas, e apenas $40 \%$ trabalham com registro em carteira (Tabela 1). De acordo com Koizumi(9), "os acidentes com motos passaram a não ser apenas de trânsito, mas também acidentes de trabalho". Estes dados são muito preocupantes, pois $43 \%$ dos entrevistados não possuíam nenhum vínculo previdenciário, ou seja, após o acidente ficaram afastados do seu trabalho, não tendo uma fonte de renda nesse período, o que agrava a situação econômica do grupo familiar.

Dos entrevistados $72 \%$ sofreram o acidente durante a semana e com $58 \%$ o acidente ocorreu durante a primeira meia hora em que estavam dirigindo. O horário de maior freqüência foi das $12 \mathrm{~h} 01$ às 18 horas (43\%), sendo que $65 \%$ estavam em horário ou percurso para o trabalho. Ressalta-se que $51 \%$ trabalhavam como motoboys (Tabela 3).

Verificamos que $59 \%$ já tinham sofrido outros acidentes de trânsito, o que comprova os riscos que correm ao conduzirem motocicletas, e também os gastos sociais e hospitalares que estão envolvidos em todo esse processo. Foram socorridos 73\% pelo Resgate e 5\% pelo helicóptero da Polícia Militar.

*Capitão do Corpo de Bombeiros da cidade de São Paulo, contato pessoal realizado no dia 09/12/2004 


\begin{tabular}{c|c|c|c|c}
\hline Questões & Condutor de Veículo a Motor & Condutor de Motocicleta & Pedestre & Passageiro \\
\hline Trabalham Informalmente & $20 \%$ & $40 \%$ & $49 \%$ & 1 a $2(65 \%)$ \\
\hline $\begin{array}{c}\text { Renda em Salários Mínimos } \\
\begin{array}{c}\text { Obedeceram às normas do Código de } \\
\text { Trânsito Brasileiro }\end{array}\end{array}$ & 3 a $4(26 \%)$ & 1 a 2 (30\%) & $54 \%$ & $0 \%$ \\
\hline $\begin{array}{c}\text { Percepção do Atendimento do Serviço } \\
\text { Social }\end{array}$ & $93 \%$ & $86 \%$ & $81 \%$ & $67 \%$ \\
\hline Lesões & $87 \%$ & $76 \%$ & $92 \%$ Fraturas & $100 \%$ Fraturas \\
\hline $\begin{array}{c}\text { Membros Acometidos } \\
\text { Número de pacientes com Fraturas } \\
\text { Expostas }\end{array}$ & $33 \%$ Membro Inferior & $68 \%$ Membro Inferior & $50 \%$ Membro Inferior & $\begin{array}{c}33 \% \text { Membro Inferior } \\
\text { Superior }\end{array}$ \\
\hline
\end{tabular}

Tabela 1 - Distribuição dos resultados mais significativos por tipo de acidente, no período de 15/08/2004 a 19/11/2004.

\begin{tabular}{l|c|c}
\hline Tipo & N. ${ }^{\circ}$ Absoluto & $\%$ \\
\hline Colisão carro x carro & 04 & 25 \\
\hline Colisão com objeto parado & 05 & 33 \\
\hline Colisão carro x caminhão & 01 & 07 \\
\hline Colisão caminhão x caminhão & 01 & 07 \\
\hline Atropelado pela própria caminhonete & 01 & 07 \\
\hline Tombamento de caminhão & 01 & 07 \\
\hline Queda do próprio carro & 01 & 07 \\
\hline Não soube referir & 01 & 07 \\
\hline Total & $\mathbf{1 5}$ & $\mathbf{1 0 0}$ \\
\hline
\end{tabular}

Tabela 2 - Descrição dos acidentes com os condutores de veículo a motor

\begin{tabular}{l|c|c}
\hline Tipo & N. ${ }^{\circ}$ Absoluto & $\%$ \\
\hline Colisão moto x carro & 20 & 54 \\
\hline Queda da motocicleta & 06 & 16 \\
\hline Colisão moto x caminhão & 02 & 05 \\
\hline Colisão moto x ônibus & 03 & 08 \\
\hline Colisão moto x moto & 02 & 05 \\
\hline Colisão moto x cachorro & 01 & 03 \\
\hline Prensado por dois carros & 01 & 03 \\
\hline $\begin{array}{l}\text { Queda seguida de atropelamento } \\
\text { por um ônibus }\end{array}$ & 01 & 03 \\
\hline Não soube referir & 01 & 03 \\
\hline Total & $\mathbf{3 7}$ & $\mathbf{1 0 0}$
\end{tabular}

Tabela 3 - Descrição dos acidentes com os dos condutores de motocicletas

Os motociclistas usavam: capacete fechado (92\%); refletivo na roupa (32\%); roupa de couro (22\%); só a jaqueta (19\%); roupa de chuva (16\%). A maioria possuía habilitação (89\%). Segundo Greve(10) "para os motociclistas é importante o uso de roupas adequadas que podem amortizar uma queda e diminuir o impacto durante a queda. Porém, para o motociclista é fundamental o respeito às leis de trânsito, visto que são os mais exposto aos acidentes e tem alta possibilidade de sofrer lesões graves".

\section{Pedestre}

Foram entrevistados 26 pedestres, sendo a maioria do sexo masculino (62\%) com idade variando entre 39 e 48 anos (27\%). Salientamos que 15\% dos entrevistados estavam na faixa dos 09 aos 16 anos. Segundo Mello Jorge(11), " em São Paulo tem sido possivel demonstrar que em cerca de $60 \%$ das mortes por acidentes de trânsito a vítima é o pedestre, o percentual se eleva a $75 \%$, quando se estudam somente os óbitos dos menores de 15 anos" (Tabela 4).

\begin{tabular}{l|c|c}
\hline Tipo & $\mathrm{N}^{\circ}{ }^{\circ}$ Absoluto & $\%$ \\
\hline Atropelado por carro & 19 & 72 \\
\hline Atropelado por ônibus & 02 & 08 \\
\hline Atropelado por caminhão & 02 & 08 \\
\hline Atropelado por moto & 01 & 04 \\
\hline Não soube referir & 02 & 08 \\
\hline Total & $\mathbf{2 6}$ & $\mathbf{1 0 0}$ \\
\hline
\end{tabular}

Tabela 4 - Descrição dos acidentes com pedestres
Em relação ao nível de escolaridade, 43\% possuem apenas o ensino fundamental incompleto; $50 \%$ trabalham informalmente (Tabela 1); 61\% são solteiros; $80 \%$ residem em São Paulo; apenas $8 \%$ encontravam-se em situação de rua. Quando questionados sobre a imprudência no momento do acidente, os pesquisados referem que a culpa foi do motorista do veículo a motor (35\%); 14\% assumem sua imprudência e $15 \%$ de ambos. O horário do acidente na maioria dos casos foi entre as $18 \mathrm{~h}$ e $24 \mathrm{~h}$ (38\%), no domingo (27\%), e os pacientes foram socorridos pelo Resgate (69\%). Ressalta-se que $96 \%$ dos entrevistados não receberam nenhuma assistência do atropelante.

\section{Passageiro}

Foram internados apenas seis passageiros no período da pesquisa: quatro passageiros de carro transportados no banco traseiro sem cinto de segurança; uma criança transportada na carroceria de um caminhão de mudança e um garupa de motocicleta que usava somente o capacete. Dos acidentados: $83 \%$ foram do sexo masculino; 66\% com idade entre 21 a 30 anos; 34\% tinham ensino médio completo. Sobre o acidente, $50 \%$ declararam ter sido culpa do motorista do carro. Quanto ao momento do acidente 66\% ocorreram na sexta-feira e 100\% no horário das 18h às 6 horas. Percebemos que a maioria dos entrevistados se acidentou de noite/ madrugada, o que demonstra que estavam suscetíveis a acidentes, prevalecendo a questão do sono, alta velocidade e alcoolemia, etc. A Polícia Militar socorreu 83\% destas vítimas (Tabela 5).

\begin{tabular}{l|c|c}
\hline Tipo & N. ${ }^{\circ}$ Absoluto & $\%$ \\
\hline Colisão carro x carro & 01 & 17 \\
\hline Colisão carro x moto & 01 & 17 \\
\hline Colisão caminhão x caminhão & 01 & 17 \\
\hline Perda da direção na curva e batida em árvore & 02 & 32 \\
\hline Tombamento de carro & 01 & 17 \\
\hline Total & $\mathbf{0 6}$ & $\mathbf{1 0 0}$ \\
\hline
\end{tabular}

Tabela 5 - Descrição dos acidentes com os passageiros.

Um dado muito interessante é que quando perguntados sobre as condições do motorista que estavam acompanhando, 50\% não sofreram nenhuma lesão grave e um foi liberado no mesmo dia. Entretanto, dois faleceram (33\%), o que mostra a gravidade dos acidentes quando os passageiros ficam internados, visto que nos dois casos em que faleceram os condutores do veículo, faleceram também os passageiros do banco dianteiro. Ressalta-se que em um caso que o motorista não sofreu nada grave, o passageiro do banco dianteiro faleceu. No caso da criança que era transportada no caminhão (na carroceria), houve o falecimento de duas pessoas no acidente: um ciclista que foi atropelado pela outra carreta que bateu atrás e um passageiro que também estava em cima da carroceria do caminhão atingido.

\section{DISCUSSÃO}

Antes de fazermos qualquer análise, devemos compreender qual é a lógica do trânsito e todas as variáveis que o cercam. De maneira 
geral, percebemos que a maioria dos pacientes entrevistados é jovem, do sexo masculino (Figura 3) e isso traz muitas angústias e questões sociais amplas a serem trabalhadas. Esta demanda para o Serviço Social vem crescendo muito. São mobilizados para o atendimento de cada caso: uma sistemática de ações, procedimentos, habilidades e domínios técnicos necessários para as intervenções sociais que dificultam o tratamento do paciente que, em geral, fica um longo tempo em reabilitação (Figura 4).

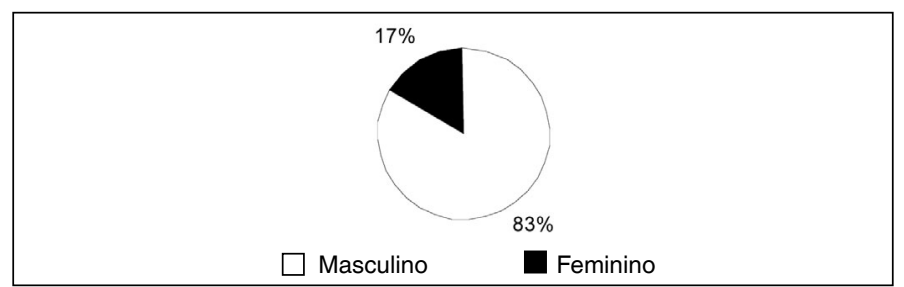

Figura 3 - Sexo dos pacientes entrevistados na pesquisa no período de $15 / 08 / 2004$ a 19/11/2004.

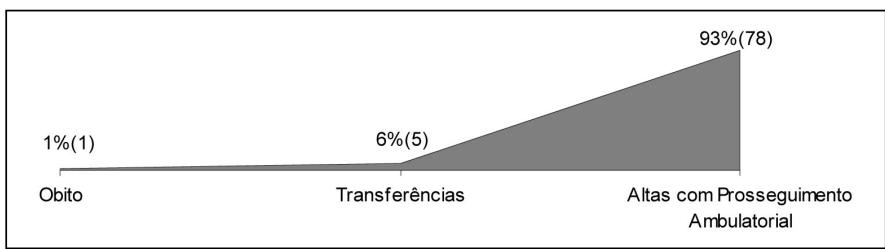

Figura 4 - Destino dos pacientes após alta do Pronto-Socorro do Instituto de Ortopedia e Traumatologia no período de 15/08/2004 a 19/11/2004.

Outra questão interessante demonstrada nesta pesquisa é que se acidentam com mais freqüência os motociclistas e em segundo lugar os pedestres (Figura 2). Isso mostra e comprova a vulnerabilidade que estes sofrem nas vias públicas. Estão expostos cotidianamente a maiores riscos, conforme noticiam, inclusive, os jornais de grande circulação. Os motoboys entrevistados já possuíam registrados em seus prontuários médicos no Hospital das Clínicas várias ocorrências em hospitais com diagnósticos de alto custo, o que gera um gasto imenso na rede pública.

As grandes empresas fabricantes de motos e as empresas seguradoras do veículo não participam e não arcam com as despesas que estes pacientes produzem nos hospitais. Cada vez mais as empresas colocam inúmeras facilidades como baixo custo e financiamentos diversos para a aquisição de motocicletas. Deveriam investir mais na segurança destes motociclistas.

Os dados nos revelaram que o número de acidentes de trabalho e de percurso são altíssimos, visto que no desempenho de suas atividades profissionais estes pacientes como a população em geral estão sujeitos a diversos riscos. O assistente social é fundamental no Pronto-Socorro, pois as orientações previdenciárias dadas aos pacientes são a base para que estes recorram aos seus direitos, não ficando desamparados economicamente no período de sua reabilitação, uma vez que, de modo geral, a reabilitação ortopédica e a alta exigem um período muito longo.

É muito importante refletir sobre o uso de cinto de segurança no banco traseiro. Hoje em dia, as pessoas respeitam e utilizam o cinto no banco dianteiro devido às multas ou mesmo pela conscientização da necessidade do uso divulgado através da mídia. Mas o uso do cinto no banco traseiro é diferente, a população em geral não o utiliza, nem valoriza a sua necessidade. As multas devido à não utilização do cinto traseiro são dificultadas pela visualização. O trabalho educativo e preventivo é primordial nestes casos, pois atuar nas causas é bem mais fácil do que nos efeitos que são os graves acidentes de trânsito e suas diversas seqüelas.

Vale ressaltar a questão dos pedestres que, ao se acidentarem, não recebem na maioria dos casos nenhuma ajuda do seu atropelante. A situação é muito delicada porque além de sofrerem um acidente, não recebem nenhuma retaguarda daquele que causou o acidente, a não ser que a vítima entre posteriormente com uma ação judicial de perdas e danos. Desta forma, deveria se pensar na criação de penas alternativas, ou mesmo na obrigatoriedade dos atropelantes em dar uma retaguarda adequada para estas vítimas que, em geral, trazem seqüelas físicas e emocionais por longo tempo de suas vidas.

Os entrevistados, em grande parte, relataram estar de acordo com as normas do Código de Trânsito Brasileiro - CTB (Tabela 1) e atribuíram a culpa ou imprudência do acidente a terceiros. Este fato demonstra que, nos casos de condutores de veículos a motor e motocicletas, estes têm por obrigatoriedade conhecer as leis, visto que a maioria possui habilitação para dirigir. No caso dos pedestres, 35\% revelaram não estar de acordo com as normas do CTB (Tabela 1). Percebemos com isso que as normas do Código de Trânsito para este grupo não são conhecidas e que a população desconhece os seus direitos e deveres enquanto pedestres e usuários do sistema de trânsito. Devem ser realizados trabalhos preventivos de melhor qualidade para se chegar mais próximo da conscientização ou mesmo da reflexão sobre os acidentes de trânsito e suas conseqüências físicas e sociais.

Ressalta-se que, na maioria expressiva dos casos, os pacientes já sofreram outros acidentes de trânsito, o que indica reincidência de internações e de acidentes diversos, evidenciando ainda os altos custos sociais e hospitalares destes pacientes. Um acidente de trânsito acarreta inúmeras despesas e perdas, tanto do aspecto financeiro, familiar, hospitalar, de reabilitação, de previdência, danos públicos, etc. São necessários trabalhos contínuos de prevenção aos acidentes de trânsito, já que o número de pacientes é crescente.

A emergência/urgência é o lugar onde se dá o inesperado, e o assistente social deve estar preparado para atender os diversos conflitos e orientar os pacientes de seus direitos sociais como: seguro obrigatório, indenização, acidente de trabalho, encaminhamento, localização de familiares, trabalho em rede com outras instituições, ou mesmo atuar como retaguarda médico-social nos casos de moradia inadequada ou falta de residência, tudo de acordo com a necessidade apresentada pelos pacientes (Anexo I).

\section{Pesquisa Qualitativa}

\section{Você recebeu alguma informação do Serviço Social durante a internação} hospitalar?

"Orientou-me sobre a previdência, seguro obrigatório, localizou meus familiares, conseguiu uma casa para eu ficar depois da alta, ajudou com a passagem para os meus familiares virem me visitar" (discurso do sujeito coletivo).

\section{Você consegue detectar o trabalho do Assistente Social?}

"Encaminha as pessoas, informa, ajuda, verifica as questões de locomoção e faz um trabalho educativo e social" (discurso do sujeito coletivo).

Como se sente diante da internação hospitalar devido ao acidente de trânsito?

"Sinto-me mal, por medo, por não fazer o que podia habitualmente, não poder ajudar minha família, por saber que vou operar, inconformado, apreensivo, pela humilhação, prejuízo, é horrível ficar internado" (discurso do sujeito coletivo).

\section{Que tipo de apoio tem recebido ou espera receber?}

"Espero receber apoio da família, amigos, vizinhos, da empresa, do INSS, do governo, de conhecidos e do hospital" (discurso do sujeito coletivo).

\section{Qual é a sua opinião para acabar ou diminuir os acidentes de trânsito?}

"Ter mais atenção de todos, mais conscientização, o Detran deve fazer exames mais rígidos, fazer curso de direção defensiva, ter mais responsabilidade. Mudar as leis, as leis deveriam ser mais severas, deveriam prender os irresponsáveis e não apenas processá-los. Melhorar o transporte público, pois diminuiria os carros nas ruas" (discurso do sujeito coletivo).

Anexo I - Questionário: Na pesquisa qualitativa descrevemos os resultados mais relevantes. 
Outro dado muito interessante é como estes pacientes se sentem diante da internação hospitalar causada pelo acidente de trânsito (Anexo I).Os pacientes, vítimas do inesperado, passam de uma condição ativa para uma situação de dependência. Os profissionais que atuam na área da saúde devem respeitar e entender todas as angústias e preocupações que os pacientes sofrem no momento da internação. Alguns mencionam sentimentos de "humilhação", "dependência" e "medo" (Anexo I). Enfim, por mais que se mude a palavra, observamos que a questão da internação é um período de grandes conflitos emocionais para o paciente e seus familiares. A equipe de saúde deve atuar nesta fase de maneira interdisciplinar, compreendendo o paciente em sua totalidade.

\section{CONCLUSÃO}

Um trabalho educativo e preventivo, voltado para o paciente vítima de violência no trânsito, deve ser realizado pelos profissionais da equipe de saúde, pois este tornou-se um problema de saúde pública tendo em vista os altos números de acidentes e atendimentos no serviços públicos de emergência. Percebemos que o Estado necessita implementar políticas públicas voltadas principalmente para a revitalização do transporte coletivo, programas de educação e conscientização para evitar o consumo de bebidas alcoólicas no trânsito.

Diante disto, sugerimos que este tema seja explorado e aprofundado cientificamente, para que novos projetos possam surgir e reduzir os acidentes de trânsito e toda a realidade social e de saúde que os envolve.

\section{REFERÊNCIAS BIBLIOGRÁFICAS}

1. Caldas G. Novo código de trânsito brasileiro anotado. São Paulo: Ediprax Jurídica; 1998.

2. David LH. O trauma ortopédico é uma subespecialidade?. Traduzido por Arnaldo Valdir Zumiotti. Folha Ortop Traumatol. 2004; 39:14-5.

3. Oncken L. Violência no trânsito precisa ter fim. Rev Assoc Paul Med São Paulo. 2004; (545):18-9.

4. Instituto de Pesquisa Econômica Aplicada. Impactos sociais e econômicos dos acidentes de trânsito nas aglomerações urbanas. Brasília: IPEA, 2003. [citado 2004 maio 12]. Disponível em URL: http://www.ipea.gov.br

5. Montal JHC. O médico, o jovem e o trânsito: acidentes de trânsito no Brasil. Rev Abramet São Paulo.2001; 39:48-9.

6. Ministério da Saúde / Departamento Nacional de Trânsito. [citado 2004 maio 03]. Disponível em URL: http://www.denatran.com.br
7. Levèfre F. Discurso do sujeito coletivo: um novo enfoque em pesquisa qualitativa (desdobramentos). Caxias do Sul: Educs; 2003.

8. Sparti SCM. Educação para o trânsito como desenvolvimento de consciência: um estudo com universitários/as [tese]. São Paulo: Pontifícia Universidade Católica de São Paulo/PUC; 2003.

9. Koizume MS. Acidente de trabalho. Jornal da Tarde de São Paulo - 17/01/01. [citado 2001 maio 25]. Disponível em URL: http://safetyguide.com.br/noticias

10. Greve JMD. Traumatismo raquimedulares (TRM) nos acidentes de trânsito $e$ o uso de equipamentos de segurança. Jornal da Abramet maio/dezembro; 1996. p.19-21

11. Mello Jorge MHP. Acidentes de trânsito: um problema de saúde pública, uma questão de cidadania. In: Lener J. Cidadania, verso e reverso. São Paulo: Imprensa Oficial do Estado; 1997/1998. 